\title{
AETIOLOGICAL FACTORS OF INFERTILITY: A STUDY DONE IN BANGABANDHU SHEKH MUJIB MEDICAL UNIVERSITY (BSMMU) HOSPITAL - A TERTIARY LEVEL HOSPITAL IN BANGLADESH
}

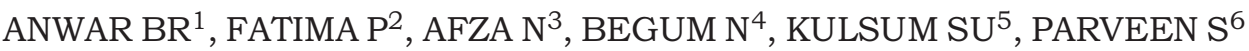

\begin{abstract}
:
Background: Infertility is defined as the failure in pregnancy after one year of unprotected intercourse. Several centers have reported different causes of infertility. The aim of the present study was to find out the aetiological factors of infertility in Bangabandhu Sheikh Mujib Medical University (BSMMU) Hospital, which is a tertiary level hospital in Bangladesh.
\end{abstract}

Methods: This cross sectional study was done at the Out Patient Department of infertility in BSMMU Hospital between December 2004 and March 2005 based on a semi-structured questionnaire. One hundred infertile couple with necessary investigations were taken for the study.

Result: In this study, primary and secondary infertility were found in 56\% and 44\% patients respectively. Among 100 couples, 57\% had female factor, 25\% had both male and female factors and in 3\% had male factor and in 15\% of couple, the causes of infertility were unknown. Among women, there were tubal factor in 33\%, ovarian factor in 12\% and endometriosis in $11 \%$. In this study, tubal blockage after menstruation regulation (MR) was detected in $50 \%$ cases of female secondary subfertility. Result showed $82 \%$ of men had normal spermogram, and $28 \%$, had sperm disturbance including oligospermia, asthenospermia, oligoasthenospermia and teratospermia.

Conclusion: Although female factor was the most common cause of infertility in BSMMU, we cannot conclude it as final. We suggest more similar researches with larger sample size in different institutions to evaluate most common causes of infertility in Bangladesh.

Key words: Infertility, subfertility, aetiological factors, unexplained factors.

J Dhaka Med Coll. 2012; 21(2) : 152-155.

\section{Introduction:}

Infertility is defined as the inability of a couple to achieve conception after one year of unprotected coitus. It affects one in seven couples $^{1}$. The levels and patterns of infertility apparently vary widely and also are different in developed countries compared to those in developing region of the world ${ }^{2}$. Cultural, socioeconomic, health care practices and policies and environmental factors play a major role in the prevalence and etiology of infertility $^{3}$. Also the proportions of causes of infertility have changed over time ${ }^{(4)}$. The most cost-effective approach to solving the infertility problem is prevention and education. Further research in both developed and developing countries is needed to understand the high prevalence and causes of infertility ${ }^{5}$. There are only a few reports on this topic in Bangladesh ${ }^{6,7}$. Therefore, determination of the clinical patterns and a review of the major causes of infertility in BSMMU, Bangladesh was the main objective of this study.

1. Dr. Begum Rokeya Anwar, Junior Consultant, Department of Obstetrics \& Gynaecology, Savar Upazila Health Complex, Savar, Dhaka.

2. Prof. Parveen Fatima, Head, Department of Infertility, Bangabandu Sheikh Mjuib Medical University (BSMMU), Dhaka.

3. Dr. Nasim Afza, Assistant Professor, Department of Obstetrics \& Gynaecology, Dhaka Medical College, Dhaka.

4. Dr. Nazneen Begum, Assistant Professor, Department of Obstetrics \& Gynaecology, Bangabandu Sheikh Mjuib Medical University (BSMMU), Dhaka.

5. Syeda Umme Kulsum, Assistant Professor, Department of Obstetrics \& Gynaecology, Z. H. Sikder Women's Medical College, Dhaka.

6. Dr. Shaila Parveen, Assistant Professor, Department of Obstetrics \& Gynaecology, National Institute for Cancer Research and Hospital (NICR\&H), Dhaka. 


\section{Methods:}

This cross-sectional study was done at Out Patient Department (OPD) of Infertility at Bangabandhu Sheikh Mujib Medical University (BSMMU) Hospital, between December 2004 and March 2005. 100 Couple with more than one year of sub-fertility were reviewed through a semi-structured questionnaire, where necessary investigations were done to detect aetiological factors. Infertile woman above 45 years of age and couples without necessary investigations were excluded from the study.

A questionnaire was designed encompassing all clinical information. It also included investigations done to detect causes of infertility. Data were collected from the review of 100 infertile couples attending the out patient department (OPD) of infertility of Bangabandu Sheik Mujib Medical University (BSMMU). Detailed history was taken; complete Physical examination and investigation in the female partners were done to confirm etiology responsible for female factor infertility. The specific investigations performed for the female partners included tests for documentation of ovulation (gonadotrophins and steroids assays and ultrasonography), test for tubal patency (hysterosalpinography) and loparoscopy (when indicated e.g tubal diseases, endometriosis etc.). For male, reports of semen analysis were studied to detect male factors of infertility.

All the patients were given a comprehensive explanation and written informed consent was taken. Then collected data were analyzed by using SPSS version 11.0.

\section{Result:}

A total of 100 infertile couples were assessed in this study. Of them, $45(56 \%)$ couples had primary infertility and 37 (44\%) had secondary infertility. The mean age of the women was $27.73 \pm 3.46$ (range 18- 40 years) the mean duration of infertility at the time of presentation to infertility unit was $4.3 \pm 0.46$ years. The BMI of female partner was 23.16 \pm 1.08 (rage 20-29 $\mathrm{kg} / \mathrm{m}^{2}$ ). The number of middle classes were attending in hospital was about $59 \%$ with monthly income of mean $5813 \pm 895.4$ taka per months.
In this study, only female and male factors were responsible in $57 \%$ and $3 \%$ cases respectively (Table-I). In $25 \%$ cases both male and female were responsible as combined factor infertility, remaining $15 \%$ were unexplained infertility and Female factors were responsible for sub fertility in $82 \%$ cases. Among them 56\% were primary sub fertility and $44 \%$ were secondary sub fertility (Table-II). The ratio of primary and secondary infertility was 1.2:1. Regarding secondary infertility 18 cases (48.65\%) were related to MR out of 37 cases.

Among women, different infertility factor included: Female factors responsible for infertility were in $82 \%$ cases (Table-III). The most common cause of female infertility was tubal factor and it was identified in $33(40 \%)$ women by laparoscopy or hysterosalpingography (HSG). Hypothyroidism was the second most common etiologic factors and identified in 20 $(24.39 \%)$ of infertile women by hormonal assay and clinical manifestation. Endometriosis was diagnosed in $12(14.46 \%)$ cases by laparoscopy as chocolate cyst in 7 cases and obliteration of pouch of doglus in 5 cases. Polycystic ovary syndrome was identified in $11(13.41 \%)$ women by ultrasonography, hormonal assay and clinical manifestation. Hyper prolactinemia was detected as the sole cause of infertility in $4(4.88 \%)$ cases. Uterine factor was recognized in 2 women. One woman was with fibroid uterus and another with Asherman's syndrome.

Results of semen analysis showed that $72 \%$ of men had normal spermogram. No couple had azospermia, and $28 \%$ had sperm disturbance such as oligospermia, asthenospermia, oligoastheno -spermia and teratospermia (Table-IV).

Table-I

Types of infertility $(n=100)$

\begin{tabular}{lcc}
\hline Type of Infertility & $\begin{array}{c}\text { Number of } \\
\text { Patients }\end{array}$ & Percentage \\
\hline Male & 3 & $3 \%$ \\
Female & 57 & $57 \%$ \\
Combined & 25 & $25 \%$ \\
Unexplained & 15 & $15 \%$ \\
\hline
\end{tabular}


Table-II

Incidence of infertility $(n=100)$

\begin{tabular}{lcc}
\hline Type of Infertility & $\begin{array}{c}\text { Number } \\
\text { of patients }\end{array}$ & Percentage \\
\hline Primary & 45 & $56 \%$ \\
Secondary & 37 & $44 \%$ \\
\hline
\end{tabular}

Table-III

Female Causes of infertility $(n=82)$

\begin{tabular}{lcc}
\hline $\begin{array}{l}\text { Cause of } \\
\text { Infertility }\end{array}$ & $\begin{array}{c}\text { No. of } \\
\text { Patients }\end{array}$ & Percentage \\
\hline Tubal & 33 & $40.24 \%$ \\
Hypothyroid & 20 & $24.39 \%$ \\
Endometriosis & 12 & $14.46 \%$ \\
PCO & 11 & $13.41 \%$ \\
Hyper Prolactinemia & 4 & $4.88 \%$ \\
Uterus & 2 & $2.44 \%$ \\
\hline
\end{tabular}

Table-IV

Semen Analysis ( $n=100)$

\begin{tabular}{ll}
\hline Parameters & $\begin{array}{c}\text { Number of Percentage } \\
\text { Patients }\end{array}$ \\
\hline
\end{tabular}

Sperm count (million/ml)

$\begin{array}{lcc}\text { a. } \text { No sperm } & 0 & 0 \% \\ \text { b. }<20 & 9 & 9 \% \\ \text { c. }>20 \text { and above } & 91 & 91 \%\end{array}$

Sperm morphology

$\begin{array}{lcc}\text { a. }<30 \% \text { normal } & 16 & 16 \% \\ \text { b. }>50 \% & 84 & 84 \% \\ \text { a. non motile } & 3 & 3 \% \\ \text { b. }<30 \% \text { motile } & 16 & 16 \% \\ \text { c. }>30 \% & 81 & 81 \%\end{array}$

\section{Discussion:}

In this study, a relatively high frequency of primary infertility (56\%) was observed. While secondary infertility was determined in $44 \%$ of couples. These findings are comparable with that of Shayela and Banu's study which was done in the same institute in 1989 and 1993 respectively ${ }^{6,7}$. The most comprehensive study of infertility - a WHO study of 5800 infertile couples seeking help at 33 medical centers in 22 developed and developing countries- found that most infertile couples around the world suffer from primary infertility ${ }^{8}$. Sub- Saharan Africa is an exception, where most couples $(52 \%)$ suffered from secondary infertility ${ }^{8}$. The mean age of female partners were $27.73 \pm 3.46$ years which are almost similar to some other reports ${ }^{9,10}$ from different countries.

In our study, $66 \%$ couple reported with in 5 years of marriage. Among them only 20\% reported with in 2 years of infertility. Mean duration of infertility at the time of presentation in the infertility unit $4.3 \pm 46$ years (range 210 years). Study of infertility by Malekshah showed that the duration of infertility was longer $(5.7 \pm 4 \text { years })^{11}$. Infertile couples do not usually present in time to the infertility clinics due to inadequate general knowledge regarding infertility and about the presence of special centers in the country. Early attendance of infertile couple in their young age with lower duration of sub-fertility in infertility unit will be helpful for early assessment. They could be able to take best available method of treatment in their most fertile period.

The causes of infertility can be divided into four major categories: the female factor, the male factor, combined factors and unexplained infertility. Female and male factors were responsible in $57 \%$ and $3 \%$ cases respectively. In $25 \%$ cases both male and female were responsible as combined factor infertility; remaining $15 \%$ were unexplained infertility. Study of infertility by Malekshah showed in his study male factor consists $38.9 \%$ of infertility, female factor occurred in $34.7 \%$ of the infertile couples, in $14.6 \%$ of the couples both partners were involved and in $11.8 \%$ of couples no cause could be ascertained (11). Female factors responsible for sub fertility were in $82 \%$ cases (Table 3$) .33$ cases $(40 \%)$ were due to tubal factors. Endometriosis and poly cystic ovrian syndrome (PCO's) were 12 (14.63\%) and 11 $(13.41 \%)$ cases respectively. In a field study in central part of Iran (Yazd province), Aflatoonian et al. (2009) reported female factor as the main cause of infertility (57.7\%) (12). In my study $33 \%$ cases were due to tubal factor whereas in Africa the incidence of tubal factors infertility is very high at $85 \%$ (13). Tubal occlusion is 
more prevalent in African countries because frequency of poorly treated STD is high (14-15). A survey of infertility in Royan Institute by Kamali showed that most common cause of female infertility were ovarian factors $(20.36 \%)$ (10) and tubal factor infertility was $12.64 \%$, was mainly due to secondary Tuberculosis (TB). Though TB is highly prevalent in Bangladesh only $3 \%$ infertile couple gave a past history of TB.

In this study, male factors were responsible in 28 cases (Table 4). Semen analysis report of 9 cases showed oligospermia i,e sperm count $<20$ million $/ \mathrm{ml}$. There was no case of azoospermia. In sperm motility in $3 \%$ cases it was totally non motile. In 16 cases motility was $<30 \%$.

Kamali in his study showed that sperm disturbance $(40.3 \%)$ such as oligospermia, asthenospermia, oligoasthenospermia and teratospermia were the most common etiologic factors responsible for male infertility ${ }^{10}$.

In our study, history of infertility in first degree relatives was positive in $22 \%$ of women and $11 \%$ of men. Kamali at all identified history of infertility in first degree relatives was positive in $8.9 \%$ women and $10 \%$ men $^{10}$. Therefore, a positive correlation between family histories of infertility in cases of infertile couple may be a possibility. Further study needed to prove association with it.

\section{Conclusion:}

Bangladesh is a developing country, where population burden is a big concern for the government. On the other hand, reproduction is a basic human right; infertility leads to physical, psychological and social problem. Government needs to take care of infertility carefully, considering the above issues. It is recommended to take measures to improve the referral system, fertility health education and implementing infertility prevention programs.

\section{References:}

1. Royal College of Obstetricians \& Ghynecologists. The initial investigation and management of the infertile couple. Guideline. London : RCOG: 2001.
2. Kds A, Nguyen T. Infertility in developing countries. Reproductive Health Outlook 1997; 15: $1-14$.

3. Leke RJ, Bassol-Mayagoitia S. Bacha AM, Grigor KM. Regional and geographical variation in infertility: effects of environmental, cultural and socioeconomic factors. Environ Health Perspect 1993; 101: 73-80.

4. Terava AN, Gissler M, Hemminiki E, Luoto R. Infertility and the use of infertility treatments in Finland; prevalence and socio-demographic determinants 1992-2004. Eur J Obstet Gynecol Reprod Biol 2008; 136: 61-6.

5. Wyshak G. Infertility in American College Alumni. Int J Obstet Gynecol 2001; 73: 237-42.

6. Shayela S. A clinical study of 100 cases of infertility attending $t$ he infertility clinic of IPGMR, Dhaka (Dissertation). Dhaka: BCPS; 1989.

7. Banu LH. Clinical study on aetiology and diagnosis of female infertility (Dissertation). Dhaka : BCPS; 1993.

8. Cates W, Farley TMM, Rowe PJ. Worldwide patterns of infertility: is Africa different? Lancet 1985; 2: 596-8.

9. Esmeilzadeh S, Farsi M, Nazari T. The cause of infertility in the patients referring to Babol township fatemeh Zahra infertility center from May 1996 to May 1998. J Mazandaran Univ Med Sci 2002; 12: 29-33.

10. Kamali M, Kashfi F, Baghestani AR, Kashani H, Tavajohi SH, Amirchaghmagh E. The epidemiologic survey on causes of infertility in patients referred to Royan institute. Med J Tabriz Univ Med Sci 2006; 28: 103-5.

11. Mlekshah KA, Moghaddam EA. Infertility in Mazandaran province - North of Iran : an etiological study. Iranian JReprod Med 2011; 9(1): $21-4$.

12. Aflatoonian A, Seyedhassani SM, Tabibnejad N. The edidemiological and etiological aspect to infertility in Yazd province of Iran, Iranian $\mathrm{J}$ Reprod Med 2009; 7: 117-22.

13. Female Sub-fertility. In: Obstetrics and Gynecology. Vol 1. $2^{\text {nd }}$ ed. Calcutta: Orient Longman Ltd.; 1999: p.270-319.

14. Ikechebula Ji, Adinma J1, Orie EF lkegwuonu So. High prevalence of male infertility in southeastern Nigeria. J Obs Gynecol 2003; 23(6): 657-9.

15. Araoye MO. Epidemiology of infertility: social problems of the infertile couples. West Afr J Med 2003; 22(2): 109-106. 